\title{
Experimental comparison of classical PID and model-free control: position control of a shape memory alloy active spring ${ }^{\hat{2}}$
}

\author{
Pierre-Antoine Gédouin ${ }^{\mathrm{a}, 1}$, Emmanuel Delaleau, ${ }^{*, a}$, Jean-Matthieu \\ Bourgeot $^{\mathrm{a}}$, Cédric Join ${ }^{\mathrm{b}, \mathrm{c}}$, Shabnam Arbab Chirani ${ }^{\mathrm{a}}$, Sylvain Calloch ${ }^{\mathrm{d}}$ \\ ${ }^{a}$ École Nationale d'Ingénieurs de Brest, LBMS (Laboratoire Brestois de Mécanique et des \\ Systèmes - EA 4325), Technopôle Brest-Iroise, CS 73862, 29238 Brest Cedex 3, France. \\ http://www.enib.fr \\ Université européenne de Bretagne, France \\ ${ }^{b}$ Centre de recherche en automatique de Nancy, UMR CNRS 7039, Université Henry \\ Poincaré-Nancy I, Faculté des sciences et techniques, BP 239, 54506 Vandœuvre, France \\ ${ }^{c}$ Équipe-projet ALIEN, Institut national de la recherche en informatique et automatique. \\ http://www.math-info.univ-paris5.fr/ mboup/ALIEN \\ ${ }^{d}$ École Nationale Supérieure d'Ingénieurs d'Études et Techniques d'Armement, LBMS \\ (Laboratoire Brestois de Mécanique et des Systèmes, EA 4325), 2 rue François Verny, \\ 29806 Brest cedex 9, France. http://www. ensieta.fr \\ Université européenne de Bretagne, France
}

\section{Abstract}

Shape memory alloys (SMA) are more and more integrated in engineering applications. These materials with their shape memory effect permit to sim-

\footnotetext{
"This work was supported in part by the Agence nationale de la recherche (France) - Project "Tools for modelling, design and control of smart structural systems based on shape memory alloy (MAFESMA)", in part by Brest métropôle océane, in part by Conseil génénéral du Finistère.

*Corresponding author. Tel.: +33298056 650; Fax: +33 298056653 .

Email addresses: gedouin@enib.fr (Pierre-Antoine Gédouin), delaleau@enib.fr (Emmanuel Delaleau), bourgeot@enib.fr (Jean-Matthieu Bourgeot), cedric.join@cran.uhp-nancy.fr (Cédric Join), arbab@enib.fr (Shabnam Arbab Chirani), Sylvain.Calloch@ensieta.fr (Sylvain Calloch)

${ }^{1} \mathrm{P} .-\mathrm{A}$. Gédouin is partially supported by Brest métropôle océane.
} 
plify mechanisms and to reduce the size of actuators. SMA parts can easily be activated by Joule effect but their modelling and consequently their control remains difficult, it is principally due to their hysteretic thermomechanical behaviour. Most of successful control strategy applied to SMA actuator are not often suitable for industrial applications: they are particularly heavy and use the Preisach model or neural networks to model the hysteretic behaviour of these material; this kind of models are difficult to identify and to use in real time. That is why this paper deals with an application of the new framework of model-free control (MFC) to a SMA spring based actuator. This control strategy is based on new results on fast derivatives estimation of noisy signals, its main advantages are: its simplicity and its robustness. Experimental results and comparisons with PI control are exposed that demonstrate the efficiency of this new control strategy.

Key words: Nonlinear control, Model-free control, Shape memory alloy, Derivative estimation, Nonphysical modelling.

\section{Introduction}

Shape memory alloys (SMA) actuators offer the possibility to recover a known shape after a thermomechanical cycle. This property, known as the "shape memory effect", is due to the transition between the two crystallo- 
graphic phases in their composition (i.e., the transition between martensite and austenite). This variation of shape, controlled by temperature variation, can be used in the development of actuators (see e.g., Jänker et al., 2008; Peirs et al., 2002; Kohl et al., 2002). SMA can easily be heated by Joule effect, but their control is not completely solved and it is principally due to their hysteretic behaviour (see Patoor et al., 1994). Another difficulty is that the characteristics of the material are time-varying, especially during cyclic loadings. Phases kinetic transformations and 3-dimensional models are proposed in Šittner et al. (2000), Arbab Chirani et al. (2003) and Bouvet et al. (2004). These complex models can render very subtle properties of SMA, but often need to compute a finite element code, what is not suitable for real time control. On the opposite side, Robotics research has been done on SMA actuator by using simpler model and classical control method. A lot of control strategies have been applied to SMA actuators, classical PID loop are used in Calin et al. (1997), Shameli et al. (2005) and Da Silva (2007). A feedforward path is added in Majima et al. (2001) and Ahn and Kha (2007); the feedforward command is obtain by using a Preisach model for the hysteretic effect. In Dutta et al. (2005) feedforward scheme is also used but the hysteretic behaviour is described by a Duhem differential hysteresis model. In Song et al. 
(2003) and Romano and Aoun Tannuri (2009) a feedforward loop is combined with sliding mode control to obtain robustness, the feedforward path is respectively given by neural network and by a physical model. In Jayender et al. (2005), the gains of a PI controller have been tuned by $H_{\infty}$ loop shaping considering a physical model linearised around some operating points. Passivity property of the system is used in Madill and Wang (1998) to prove stability of a proposed proportional law. Nonlinear control techniques based on the Lie algebra are also used in Benzaoui et al. (1999). Even if the model is good enough, using a dynamic model for computing the control law implies the identification of the model parameters. As already mentioned, the model parameters of SMA vary during cycling, then a classical model-based control is ineffective or particularly complex. We report our experience, where industrial partners still explain that in order to realise the process control, the part of process modelling represents $90 \%$ of project global time and requires a true know-how in control and about the process to-be controlled. Indeed, the choice of the physical model structure, the identification of the model parameters, the experimental validation of model are never simple. PID controllers are often tuned with a simple (linear) non physical model (an extensive literature about this subject is available see e.g., Åström and 
Hägglund, 2005, 1995; Visioli, 2005; Ang et al., 2005; Panagopoulos et al., 2002; Khodabakhshian and Edrisi, 2008; Gyöngy and Clarke, 2006; Tavakoli et al., 2006), that is why PID control is often preferred to physical modelbased control in the industry. However, PID controllers could render poor results when a process has a large operating domain. So, how is it possible to efficiently control a complex process:

- without complex physical model ?

- with easy-to-use and theoretically understandable controllers?

In this paper, a solution ${ }^{2}$ to this difficult problem is proposed. The proposition is based on some new results in the framework of "model-free control" (see Fliess and Join, 2009; Fliess et al., 2006; Join et al., 2006). The approach uses derivative estimations (see Mboup et al., 2008, 2007; Fliess et al., 2008) which provides good results even if the measured signals are corrupted by noise. Thus a non-physical model valid a very short part of time is estimated and permits classical control design.

The present work constitutes an extension of two previous articles: In Gédouin et al. (2008), the advantages of model-free control of SMA has been high-

\footnotetext{
${ }^{2}$ See, e.g., Han (2009) for another approach.
} 
lighted by simulations while preliminary experimental results have been presented in Gédouin et al. (2009).

The paper is organised as follows: The next Section gives an introduction to the new "model-free control" and explains the design of a control law within this framework; Sec. 3 develops the model-free control of a shape memory alloys actuator and gives experimental results. Sec. 4 develops a simple improvement of the model-free controller and the PI controller; this modification results in position dependent gain of the control; this gain is obtain by steady state identification of an input-output nonphysical process model; experimental and robustness results of the modified controller are presented in great details. Sec. 5 concludes the paper and raises some perspectives.

\section{Model-free control}

Model-free control is a very recent approach to nonlinear control that has been introduced in Fliess et al. (2006), (see Fliess and Join, 2009, for a thorough presentation). A first industrial and application is reported in Join et al. (2008). 


\subsection{Derivatives of noisy signals}

We recall basics of derivative estimation. Interested reader might refer to Mboup et al. (2008) for a complete presentation. The method presented here, consists in designing FIR filters resolving a classical polynomial approximation of the signal. The polynomial approximation is obtained by algebraic manipulation of signals in the operational domain. We consider a signal $y$ that is available through a measurement $y_{m}$ corrupted by some additive noise $\varpi$, i.e. $y_{m}=y+\varpi$. The objective is to estimate time derivatives of signal $y(t)$, up to a finite order, from its measurement $y_{m}$.

The Taylor expansion of $y$ around 0 reads:

$$
y(t)=\sum_{n=0}^{\infty} \frac{y^{(n)}(0)}{n !} t^{n}
$$

Approximate $y(t)$ in the interval $[0, T], T>0$, by the polynomial $y_{N}(\tau)=$ $\sum_{n=0}^{N} y^{(n)}(0) \frac{\tau^{n}}{n !}$ of degree $N$. The operational ${ }^{3}$ analogue (see Mikusiński, 1983) $Y_{N}(s)$ of $y_{N}(\tau)$ is given by:

$$
Y_{N}(s)=\frac{y(0)}{s}+\frac{\dot{y}(0)}{s^{2}}+\cdots+\frac{y^{(N)}(0)}{s^{N+1}}
$$

It is possible to isolate each coefficient $y^{(i)}(0)$ appearing in the previous

\footnotetext{
${ }^{3}$ Reader not familiar with operational calculus can just think in terms of Laplace transform to understand the development of the derivatives estimators.
} 
expression by applying a convenient operator to $Y_{N}(s)$ (see Mboup et al., 2008, for details ${ }^{4}$ ). Indeed:

$$
\forall i=0, \ldots, N, \quad \frac{y^{(i)}(0)}{s^{2 N+1}}=\frac{(-1)^{i}}{i !(N-i) !} \cdot \frac{1}{s^{N+1}} \cdot \frac{d^{i}}{d s^{i}} \cdot \frac{1}{s} \cdot \frac{d^{N-i}}{d s^{N-i}}\left(s^{N+1} Y_{N}(s)\right)
$$

The two following formulas of operational calcul (Mikusiński (1983)) are very useful:

- the operator $\frac{1}{s^{\alpha}}$ corresponds to the function $t \mapsto \frac{t^{\alpha-1}}{(\alpha-1) !}$

- the operator $\frac{d}{d s}$ corresponds to the multiplication in the time domain by $-t$

Moreover, the Cauchy formulae to transform a multiple integral in a simple one:

$$
\int_{0}^{T} \int_{0}^{\tau_{\alpha-1}} \cdots \int_{0}^{\tau_{1}} f(\mu) d \mu d \tau_{1} \ldots d \tau_{\alpha-1}=\int_{0}^{T} \frac{(T-\mu)^{\alpha-1}}{(\alpha-1) !} f(\mu) d \mu
$$

Consequently, one obtains in the time domain the expression of $y^{(i)}(0)$ as:

$$
y^{(i)}(0)=\int_{0}^{T} P(\mu ; T) y_{N}(\mu) \mathrm{d} \mu
$$

where $P(\mu ; T)$ is polynomial in $\mu$ and $T$. Notice that (5) gives the calculation of $y^{(i)}(0)$ from an integral on the time interval $[0, T]$ for a given small $T>0$.

\footnotetext{
${ }^{4}$ Note that those operators are not unique, we have chosen here to use the ones with the least order of integration for the sake of simplicity of the presentation.
} 
As $\left.\frac{d^{i} y(t-\mu)}{d \mu^{i}}\right|_{\mu=0}=(-1)^{i} y^{(i)}(t)$ it is possible to express $y^{(i)}(t)$ as an integral which involves values of $y_{N}$ on the time interval $[t-T, t]$ :

$$
y^{(i)}(t)=(-1)^{i} \int_{0}^{T} P(\mu ; T) y_{N}(t-\mu) d \mu
$$

A simple estimator, $\left[y_{N}^{(i)}(t)\right]_{e}(N$ corresponds to the order of the truncated Taylor expansion), of the derivative $y^{(i)}(t)$ is then obtained from the noisy signal $y_{m}$ by:

$$
\begin{aligned}
{\left[y_{N}^{(i)}(t)\right]_{e} } & =\int_{0}^{1} R_{N}^{i}(\sigma) y_{m}(t-\sigma T) d \sigma \\
& =\frac{(N+i+1) !(N+1) !}{T^{i}} \int_{0}^{1} P_{N}^{i}(\sigma) y_{m}(t-\sigma T) d \sigma \\
P_{N}^{i}(\sigma) & =\sum_{k=0}^{N-i} \frac{Q_{k}^{N, i}(\sigma)}{(N-i-k) ! k !(i+k+1)} \\
Q_{k}^{N, i}(\sigma) & =\sum_{j=0}^{i} \frac{(-\sigma)^{k+j}(1-\sigma)^{N-j-k}}{j !(i-j) !(k+j) !(N-j-k) !}
\end{aligned}
$$

which is deduced from (5) by replacing $y_{N}$ by $y_{m}$ in (6) with a change of variable $\sigma=\mu T$ and by direct application of the rules of operational calculus previously given. Note that the integral operation plays the role of a low-pass filter and reduces the noise that corrupts the signal $y_{m}$. The choice of $T$ and $N$ results in a trade-off: the larger is $T$, the smaller is the effect of the noise (the larger is $T$ the better is integrals low pass filtering) and the larger is 
the error due to truncation. The larger is $N$, the smaller is the error due to truncation and the larger is the error due to noise.

In practice, the integral in (7) is evaluated using a classic composite Newton-Cotes approximation exact for a polynomial of degree $N$ using an odd number of samples $n_{s}+1$. So, $\left[y_{N}^{(i)}(t)\right]_{e}$ is evaluated at each sample time $t=k \cdot T_{s}, k=0,1, \ldots$ as the output of a FIR filter:

$$
\left[y^{(i)}\left(k T_{s}\right)\right]_{e}=\sum_{j=0}^{n_{s}} w(j) R_{N}^{i}\left(\frac{j}{n_{s}}\right) y_{m}\left((k-j) T_{s}\right)
$$

where $w(j)$ are the weights due to integral approximation and $n_{s} T_{s}=T$. We refer the reader to Zehetner et al. (2007a,b); Reger and Jouffroy (2008) for helpful complements on the implementation of these estimators.

Remark 1. When $N=i$, one can see that $R_{i}^{i}(\sigma)$ in (7) is symmetric (i.e, $\left.R_{i}^{i}\left(\frac{x+1}{2}\right)=(-1)^{i} R_{i}^{i}\left(\frac{1-x}{2}\right)\right)$ the weights due to Newton-Cotes approximation are also symmetric so the filter in (11) is a linear phased FIR filter with constant delay equals to $\frac{n_{s} T_{s}}{2}$. In the sequel, we assume that the delay is negligible for $N=i+1$ and $n_{s}=10$.

\subsection{Model-free control design}

Assume we have a plant for which we do not know any model. For the sake of simplicity of the presentation we assume that this plant is single- 
input and single-output. The control input is denoted by $u$ and the output is denoted as $y$. As seen in the previous section, we are able to estimate on-line some derivatives of $y$ and $u$. Model-free control consists in trying to estimate via the input and the output measurements what can be compensated by control in order to achieve a good output trajectory tracking. This implies the construction of a purely numerical model — also called "local model" of the plant that can be written as:

$$
y^{(\nu)}=F+\alpha u
$$

where $\alpha \in \mathbb{R}$ is a non-physical constant design parameter; $F \in \mathbb{R}$ represents all what is unknown on the system and can be compensated from the knowledge of the input-output behaviour of the system. As we have assumed that we do not know any model of the plant, the order $\nu \in \mathbb{N}$ of the numerical model (12) is necessarily a design parameter that can be arbitrarily chosen. But if we assume that the relative dominant order of the plant is known then $\nu$ will be equals to this order.

Equation (12) should not be confused with a "black-box" identified model.

\footnotetext{
${ }^{5}$ Local must be here understood in the time domain, i.e., this model is valid on a short-time horizon.
} 
In the present approach, the quantity $F$ in (12) is updated at each sampling time from the measurement of the output and the knowledge of the input: At sampling time $k$ (i.e. $t=k T_{s}$, where $T_{s}$ denotes the sampling period), the estimation of $F$ reads:

$$
[F(k)]_{e}=\left[y^{(\nu)}(k)\right]_{e}-\alpha u(k-1)
$$

where $\left[y^{(\nu)}(k)\right]_{e}$ is the estimation of the $\nu$-st derivative of the output that can be laid at time $k$ and $u(k-1)$ is the control input that has be applied to the plant during the previous sampling period.

Based on the numerical knowledge of $F$ the control for sampling period $k$ is calculated on (12) as a simple cancellation of the non-linear terms $F$ plus a closed loop tracking of a reference trajectory $t \mapsto y^{*}(t)$ :

$$
u(k)=\underbrace{-\frac{[F(k)]_{e}}{\alpha}}_{\text {NL Cancellation }} \underbrace{+\frac{y^{*(\nu)}(k)+\Delta(\epsilon(k))}{\alpha}}_{\text {Closed loop tracking }}
$$

where $\epsilon(k)=y(k)-y^{*}(k)$ is the tracking error and $\Delta(\epsilon(k))$ is a closedloop feedback controller based on the tracking error. Note that the term $-\frac{[F(k)]_{e}}{\alpha}+\frac{y^{*(\nu)}(k)}{\alpha}$ is also the "nominal control" in the "flatness-based" control of (12) (see e.g., Fliess et al., 1995; Hagenmeyer and Delaleau, 2003a,b, 2008,

\footnotetext{
${ }^{6}$ See Sira-Ramírez and Agrawall (2004) or Lévine (2009) for a complete overview of flatness-based control.
} 
2010). When the closed loop controller is of "PID" type, model-free control can be named as "intelligent PID" ( $i$-PID) (see Fliess and Join, 2009). This control scheme is summarised in Fig. 1

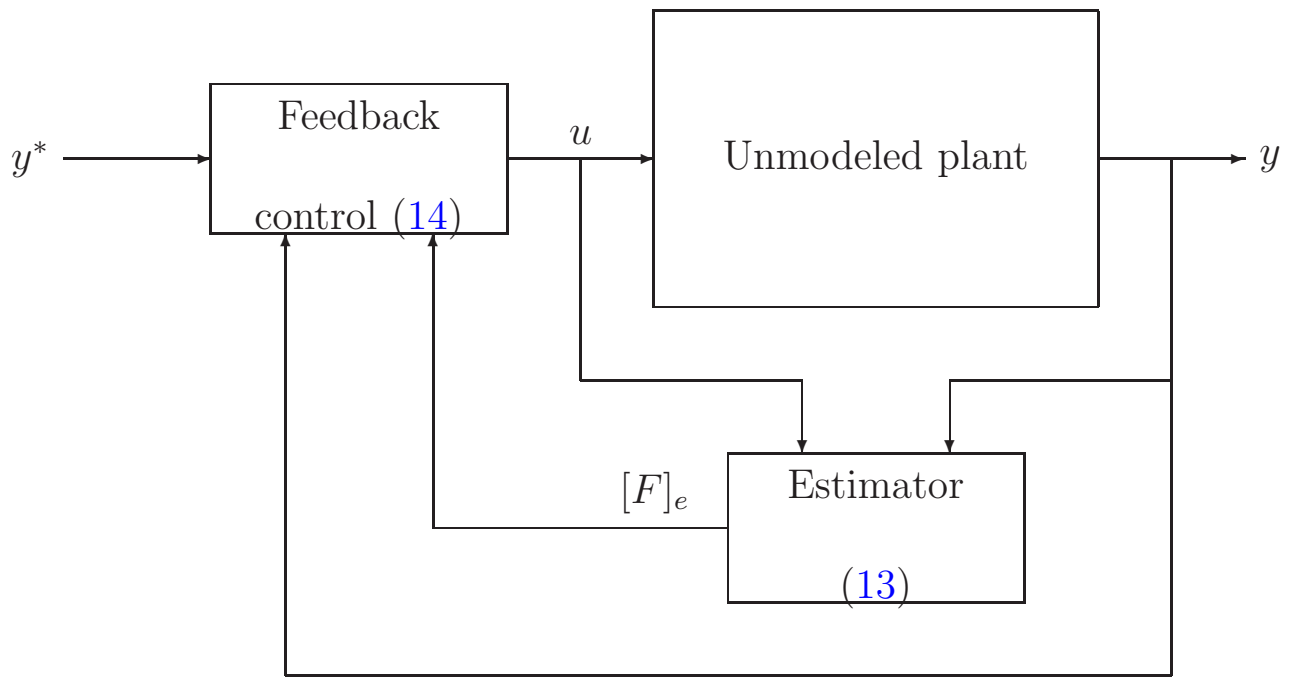

Fig. 1. Model-free control. 


\section{Prototype of SMA Actuator}

\subsection{Description of the actuator}

A simple prototype of SMA spring actuator has been built and can be seen in Fig. 2. It is constituted of a shape memory alloy spring ${ }^{7}$ in $\mathrm{Ni}-\mathrm{Ti}$ from the Mondotronics company and an aluminium mass. At room temperature the length of the spring is about $20 \mathrm{~mm}$ but the weight of the mass (450 g) deforms the spring to an initial deflection of $160 \mathrm{~mm}$, i.e. the range displacement of this actuator is about $140 \mathrm{~mm}$.

To generate a vertical displacement the spring is alternatively heated by Joule effect and cooled by free air convection:

- During heating, the martensitic phase changes into the austenite phase; the length of the spring reduces and the mass moves upward.

- During cooling, the austenite phase changes into the martensite phase; the length of the spring increase and the mass moves downward.

A fan (Not shown on Fig. 2) positioned at $110 \mathrm{~mm}$ from the spring allows to simulate a disturbance by modifying the rate of air convection.

\footnotetext{
${ }^{7}$ Coil outside diameter: $6 \mathrm{~mm}$ and wire diameter: $750 \mu \mathrm{m}$
} 
The smA spring is electrically isolated from the frame and a simple electronic circuit (not shown on Fig. 2) allows to regulated the current flowing through the spring. The heating current is measured with a shunt precision resistance and an instrumentation amplifier. The voltage applied to the spring is also measured with an instrumentation amplifier. The vertical position of the mass is measured with a laser sensor ${ }^{8}$ with a resolution of $0.3 \mathrm{~mm}$ over a range of $200 \mathrm{~mm}$ at a sampling frequency of $100 \mathrm{~Hz}$. The actuator is interfaced to a computer via a data-acquisition board ${ }^{9}$. The computer is running under Linux/RTAI ${ }^{10}$ which is a low latency kernel that allows to implement hard real-time control and measurements from C language codes.

\subsection{Position control development}

For this application, a first-order local numerical model

$$
\dot{y}=F+\alpha u
$$

is considered. The choice of a first order comes from the literature about shape memory alloy modelling in which the order is usually one (see e.g., Leclerc and Lexcellent, 1996). The control input $u$ corresponds to the electric

\footnotetext{
${ }^{8}$ OWLE 4025 FA S1

${ }^{9}$ Humusoft MF-604.

${ }^{10}$ http://www.rtai.org/
} 


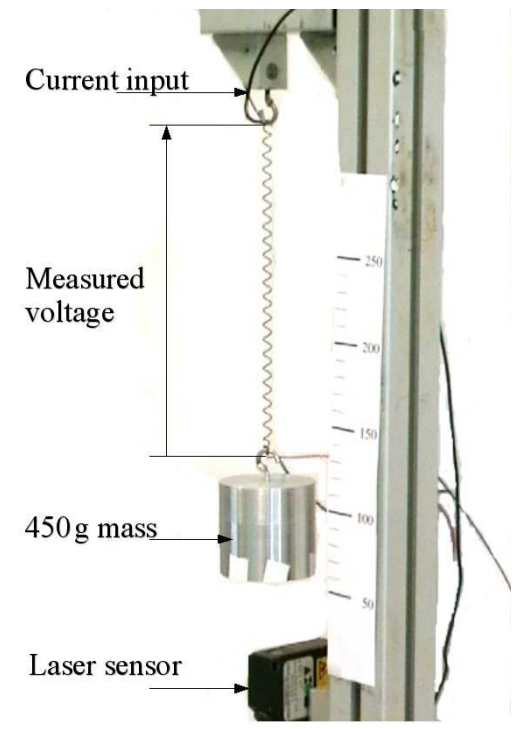

Fig. 2. Prototype of a SMA spring based actuator.

power crossing the SMA spring and the output $y$ is the measured vertical position of the mass. According to section 2.2, the control is given by:

$$
u=\frac{1}{\alpha}\left(-[F]_{e}+\dot{y}^{\star}-K_{p}\left(y-y^{\star}\right)\right)
$$

where $K_{p}$ is a positive gain. Note that as (15) is here first order, a simple proportional controller is enough to ensure convergence of the error to zero. Contrarily to classical feedback control there is no need here to add integrators in the stabilisation controller to ensure converge of the position error to zero as the model free control implicitly involves integrators. This controller is hence simply called an $i$-P controller. 
For comparison purpose, we also have implemented a classical PI control:

$$
u(t)=-K_{P}\left(y(t)-y^{\star}(t)\right)-K_{I} \int_{0}^{t}\left(y(\tau)-y^{\star}(\tau)\right) d \tau
$$

The classic control does involve an integral term in order to avoid static error.

The controller parameters have been manually tuned and are given in Tab. 1. The dynamic of the process is quite slow and, moreover, the control effect is "not symmetric" in the sense that there is no control to cool the SMA spring (cooling relies only on free air convection). Consequently, this is not possible here to apply most of the PI or PID tuning algorithms, like Ziegler \& Nichols rule. So, the tuning of the PI gains have been done in two steps: Firstly, tuning of the proportional gain on the undisturbed process (cooling fan off), secondly, tuning of the integral gain in order to achieve a good perturbation rejection. The obtained gains are, to our best expertise, the larger we can obtain in order to achieve the trade-off between dynamic precision and stability.

Similarly, the gains of the $i$-P controller have been tuned in three steps: first choose a very large $\alpha$ and a large $K_{p}$ to have a small steady-state error, then decrease $\alpha$ to obtain an oscillatory quick response of the system. Finally decrease $K_{p}$ to stabilise the system. Note that for step responses, the first derivative of the trajectory to track, $\dot{y}^{\star}$ equation (16), has been chosen 
identically zero.

The comparison is laid off in two scenarios presented in the two following sections.

\subsection{First experimental results}

\subsubsection{Scenario 1 (Fig. 3)}

We present classical closed loop step response with thermal disturbance. In this scenario the mass has to reach a reference position of $70 \mathrm{~mm}$. At time $t=60 \mathrm{~s}$ a thermal perturbations is applied using a fan (the effect of the fan on cooling speed is shown in Fig. 4) and at time $t=90 \mathrm{~s}$ the fan is switched off. Displacement of the mass (output) and electric power crossing SMA spring (input) are plotted in Fig. 3. When the actuator is controlled with the $i$-P controller, we observe that the mass reaches the reference position in approximately 8 seconds without overshoot whereas a $17 \mathrm{~mm}$ overshoot and $34 \mathrm{~s}$ response time are obtained when the actuator is controlled by a classical PI controller. This overshoot should be reduced (reducing the integral gain) nevertheless perturbations rejection would be bad. We can observe in Fig. 3(a) that the consequence of the thermal perturbation is smaller and rejected faster by the $i$-P controller than the PI one. It is clear in Fig. 3-(b) that the input dynamic is richer when it is calculated by the $i$-P controller. 
(a)

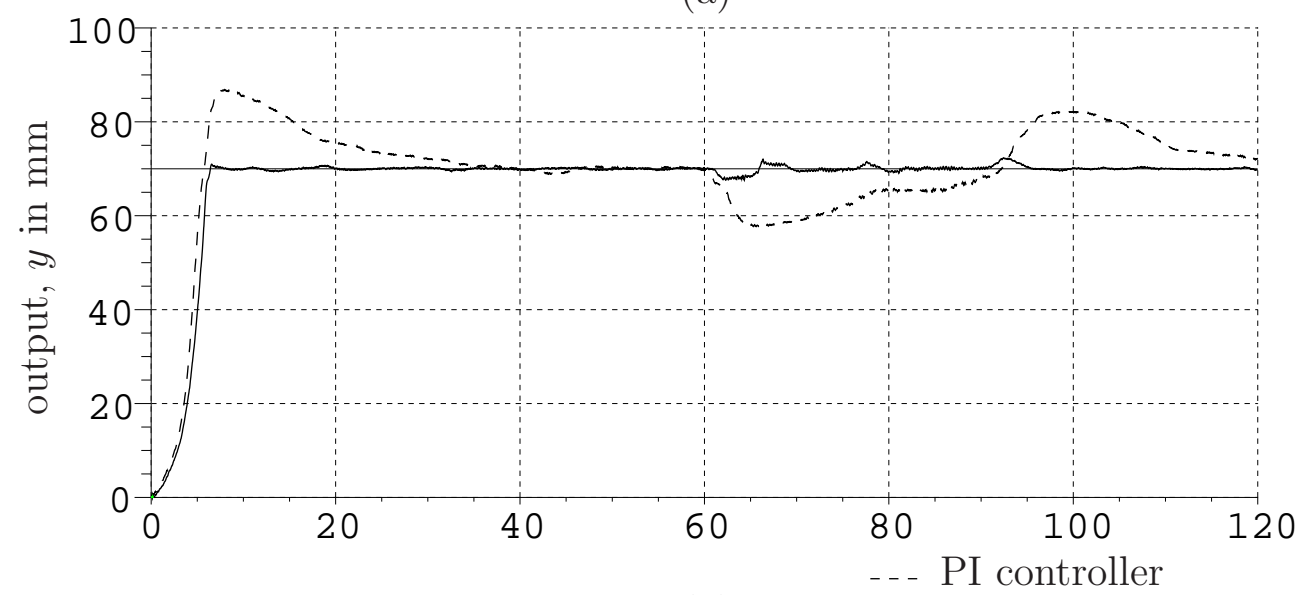

(b)

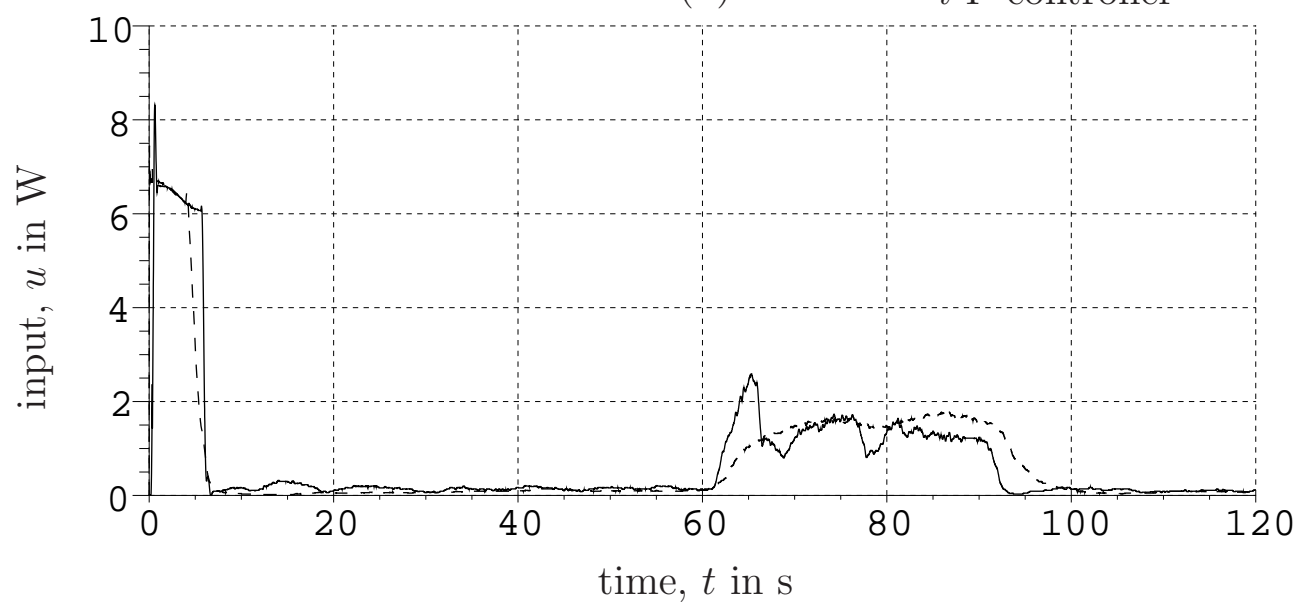

Fig. 3. (a): Output vs time for a $70 \mathrm{~mm}$ step with thermal disturbance when the actuator is controlled with a $i$-P and by a PI controller. (b): Corresponding input vs time. 


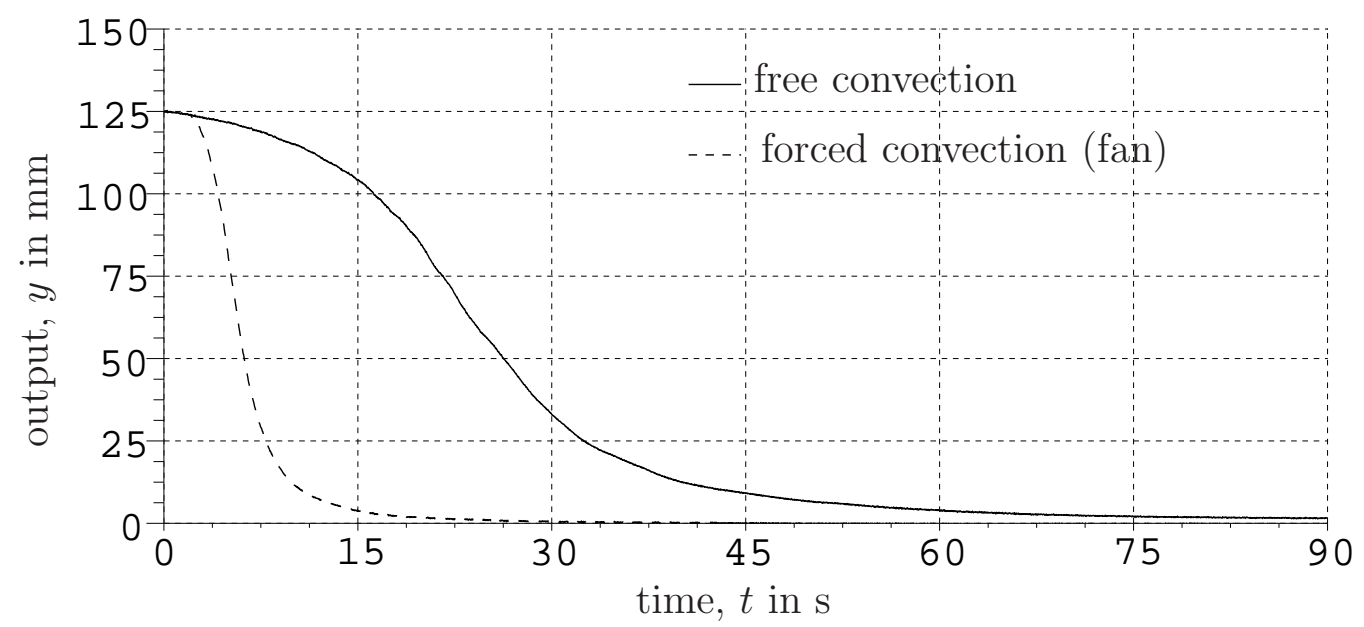

Fig. 4. Displacement of the actuator vs time during cooling by free and forced convection (with a fan).

\subsubsection{Scenario 2 (Fig. 5)}

As the control effect is "not symmetric", overshoots due to set-point jumps imply poor performances of the controllers (see for example, the response time of the plant with the PI controller). A solution to improve performances is to generate a transient profile between two set-points that the output of the plant can reasonably track. So, we present classical polynomial tracking. We can observe that tracking is slightly better when the actuator is controlled by an $i$-P (see RMS error and maximal error given in Fig. 5) however tracking performances are unsatisfactory for the two controllers. A first solution would be to increase the gains of the controllers 


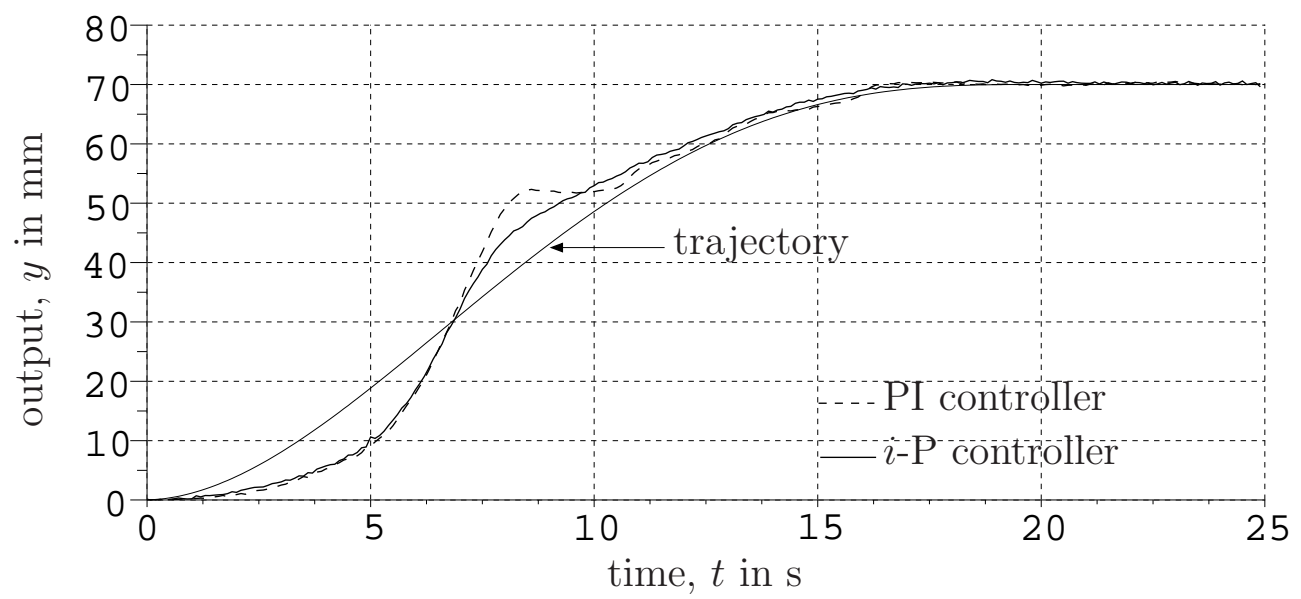

Fig. 5. Output vs time during classical tracking when the actuator is controlled with a $i$-P and by a PI controller.

but for this experiments the choice of gains level results in a trade-off: the larger are the gains the better are performances in transient however high level gains degrade performances in steady-state.

We have seen that the $i$-P controller was able to reject perturbations faster than the PI controller yet, the tracking performances are slightly disappointing. In the next section, we will modify nonlinear model-free and PI controllers using a simple off-line nonlinear nonphysical process model identification. Then we will compare robustness performances of the two controllers. 
Table 1. Controllers parameters for experiments of Sec. 3.3.

\begin{tabular}{|c|c|c|c|}
\hline & $K_{p}$ (proportional gain) & $K_{i}$ (integral gain) & $\alpha$ \\
\hline PI & $5 \times 10^{-2}$ & $4 \times 10^{-3}$ & - \\
\hline$i$-P & 0.9 & - & 600 \\
\hline
\end{tabular}

\section{Nonlinear model-free and PI controllers}

Nonphysical model process have been used in control and particularly in industrial applications since many years because models of physical processes are often difficult to obtain or are too complex to be used in real-time control. The well known Broïda and Strejc models (linear models with delay) are very popular and are still used to tune PID controllers (see e.g., Åström and Hägglund, 2001; O’Dwyer, 2006; Visioli, 2006). However linear models often become insufficient for a process with a large operating domain. In this section, we will see how the use of a very simple nonphysical input-output model, can improve the control performance of model free control on the SMA actuator. To provide a fair comparison, we also modify the PI controller in the same manner, i.e. the control law is applied through a position dependent gain. This modified PI controller is named as "non linear PI controller" in 
the sequel.

\subsection{Input-output nonphysical process model}

Some physical models of SMA actuators used in control have relative degrees equals to three and used Preisach, neural network or Prandtle-Ishlinskii model to describe hysteresis (see e.g., Ahn and Kha, 2007; Asua et al., 2008; Romano and Aoun Tannuri, 2009) but these models are difficult to identify and to use in control (see e.g., Ru et al., 2009; Wang and Su, 2006; Tan and Baras, 2004; Ram et al., 2005).

Generally, the industrialists use linear with constant delay models (LCDMs) because these models are easily and quickly identifiable, they permit to tune PI/PID controllers and to use Smith predictors. But as we have already mentioned the linear approximation could be bad for processes with large operating domains. We will try to convince the reader that MFC controllers combined with a nonlinear process model could be a good alternative to PI/PID controllers combined with LCDMs. Indeed, in some cases nonlinear models could be more precise than LCDMs and MFC controllers more robust than PI/PID controllers. That is why in this subsection we propose a type of nonlinear nonphysical process model, easy to combine with model free control, keeping in mind that the identification process must be quick and 
easy.

For a given order $\nu$, the simplest linear model used to describe a SISO system is:

$$
y^{(\nu)}=-\sum_{i=0}^{\nu-1} A_{i} y^{(i)}+B u
$$

where the $A_{i}{ }^{\prime}$ 's, $B$ and $\nu$ are constant parameters. From simulations results, we found that if $B$ is in fact significantly time varying the MFC controller yields poor performances. Indeed, in this case, the local model approximation (equation (12)) is too far from the real behaviour. One of the simplest way to improve control performances is to enrich the local model with information about the variations of $B$. To do so, we first propose a general model which is an extension of the model (18):

$$
y^{(\nu)}=-\sum_{i=0}^{\nu-1} A_{i} \operatorname{sign}(y)\left|y^{(i)}\right|^{n_{i}}+g(y) u
$$

where $g$ is a polynomial ${ }^{11}$ in $y$, the $A_{i}$ 's and the $n_{i}$ 's $\left(n_{i} \geq 1\right)$ are constant parameters which will not be necessary identified as the main information we need to improve the local model is the knowledge of $g$. Some example of response of (19) are given in Fig. 6-(b). The easiest way to identify $g$ is to use the static relation between the steady-state displacement, $y_{s s}$, and the

\footnotetext{
${ }^{11}$ Note that $g$ can also be another kind of function of $y$.
} 
applied constant input $u_{s s}$.

In steady-state equations (19) yields:

$$
-A_{0} \operatorname{sign}\left(y_{s s}\right)\left|y_{s s}\right|^{n_{0}}+g\left(y_{s s}\right) u_{s s}=0
$$

Then $g(y)=\sum_{j=0}^{s} a_{j} y^{j}$ and the parameters $A_{0}, n_{0}$ are obtained by fitting the experimental static relation between steady-state output and the corresponding input step. According to equations (20) fitting has been done by resolving ${ }^{12}$ the following minimisation problem:

$$
\min _{\left(A_{0}, n_{0}, a_{j}\right)} \sum_{i=1}^{m}\left(\left(\sum_{j=0}^{s} a_{j} y_{s s_{i}}^{j}\right) u_{s s_{i}}-A_{0} y_{s s_{i}}^{n_{0}}\right)^{2}
$$

where the set $\left(u_{s s_{i}}, y_{s s_{i}}\right) i=1, \cdots m$ consists of $m$ measured data pairs where $u_{i}$ is a constant input and $y_{s s i}$ is the corresponding steady-state output. After some trials, we have found that a polynomial of degree 3 was a good trade off between model complexity and minimal fitting residue.

$$
g(y)=a_{0}+a_{1} y+a_{2} y^{2}+a_{3} y^{3}
$$

In Fig. 6-(a) we remark a good correlation between measured data and simulation. Nevertheless, the obtained solution could be a local minimum

\footnotetext{
${ }^{12}$ The authors have chosen a classical quasi-Newton algorithm implemented in Scilab software
} 
and the model has been tested in only one situation. However the idea is not to obtain an excellent model of the process but just to have some easilyobtainable insights on its input-output behaviour to design a MFC-based robust controller and a nonlinear PI controller. Now we will see, how to modify the two controllers using the identified function $g$. Then, in Section 4.4, we will expose some experiments in closed loop.

Remark 2. Some other tests could permit to fully identify the model (19). It would then be possible to study the stability of this model controlled with the MFC controller. But as we have already mention, this model is too simple to describe the entire nonlinear behaviour of the actuator, so it seems that a stability analysis would be in this case without guarantee on the real stability of the control on the real plant.

\subsection{Design of the nonlinear model-free controller}

According to the purely numerical model (equation (12)) identified at each sample time in MFC and to the previous nonphysical model off line identified, the new local model becomes:

$$
\dot{y}=F+\alpha g(y) u
$$


(a)

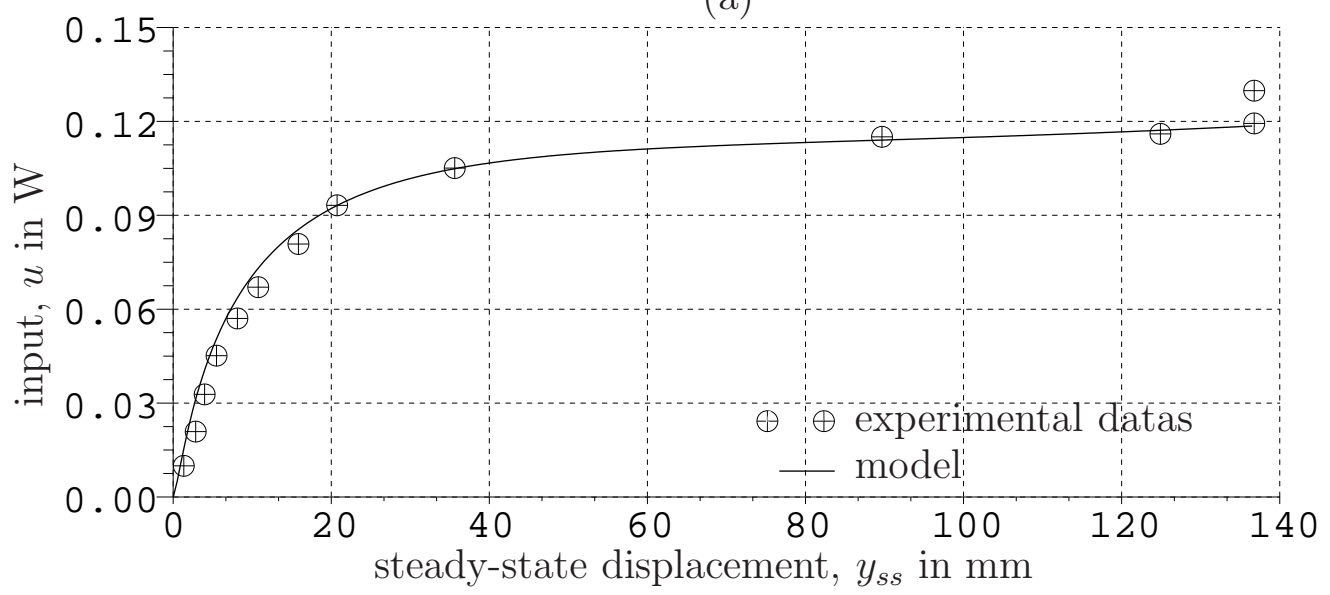

(b)

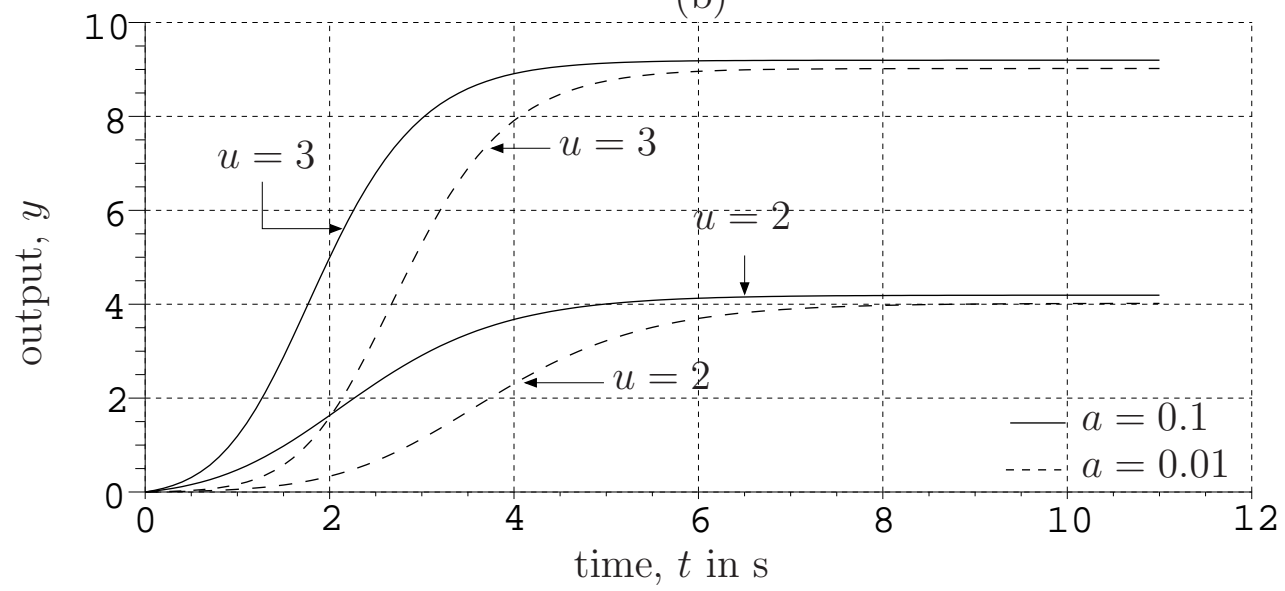

Fig. 6. (a): Experimental steady-state output (displacement) as a function of input compared with our steady-state model. (b): Responses of model (19) with $\nu=1, g(y)=a+y, A_{0}=1$ and $n_{0}=1.5$ for different values of $a$ and $u$ (steps). 
where $\alpha \in \mathbb{R}$ is a non-physical constant design parameter. The quantity $F \in \mathbb{R}$ represents all what is unknown on the system and is updated at each sampling time, replace $\alpha$ in equation (13) by $\alpha g(y)$. The control is now given by:

$$
u=\frac{1}{\alpha g(y)}\left(-[F]_{e}+\dot{y}^{\star}-K_{p}\left(y-y^{\star}\right)\right)
$$

The new control takes advantage of information obtained with the previous simple nonphysical model and of the robustness of MFC (there is still an estimation of $F$ at each sampling time).

\subsection{Design of the nonlinear PI controller}

A simple nonlinear PI controller is simply derived from the classical PI controller using the previously identified weighting function $g(y)$. It reads:

$$
u(t)=\frac{1}{g(y)}\left(-K_{p}\left(y(t)-y^{\star}(t)\right)-K_{i} \int_{0}^{t}\left(y(\tau)-y^{\star}(\tau)\right) d \tau\right)
$$

\subsection{Robustness analysis of the two nonlinear controllers}

\subsubsection{Robustness with respect to thermal disturbance and mass variation}

In this subsection, the objective is to test the robustness of the two nonlinear controllers (equations (23) and (24)). Assume that for some set-points, 
we reasonably want a response time of the plant equals to 10 seconds $^{13}$. So we design a polynomial reference trajectory with a transfer time equal to 10 seconds between the two set-points. The controller has to ensure a good tracking of this trajectory in order to achieve a response time equal to 10 seconds. In the next experiments the trajectories between set-points are polynomials of degree 5 with zero speed and acceleration at starting and ending points. We first choose a sixty-seconds scenario in which the $450 \mathrm{~g}$ mass has to reach a steady state level of $65 \mathrm{~mm}$ with a response time equals to 10 seconds and to reject a thermal disturbance in steady-state (at time $t=35 \mathrm{~s}$ a thermal perturbations is applied using the fan). Then the gains adjustment of the two controllers is done manually with the same methods as those explained in subsection 3.3. The controller parameters are given in Table 2.

Fig. 7-(a) shows the output of the plant as a function of time after the tuning procedure. After that, the following sixty-seconds experiments have been conducted keeping the same controller parameters: from the initial position, three mass of 280,360 and 750 have to reach a steady state level

\footnotetext{
${ }^{13}$ For the maximal input, the time to browse the entire displacement range is equal to 5 seconds.
} 
Table 2. Controller parameters, manually tuned and off-line identified for experiments of section 4.4 .

\begin{tabular}{|c|c|c|}
\hline & nonlinear $i$-P & nonlinear PI \\
\hline$K_{p}$ & 0.7 & 5.8 \\
\hline$\alpha$ & 10 & - \\
\hline$K_{i}$ & - & 2.8 \\
\hline$a_{0}$ & 0.81 & 0.81 \\
\hline$a_{1}$ & 0.44 & 0.44 \\
\hline$a_{2}$ & $9.19 \times 10^{-3}$ & $9.19 \times 10^{-3}$ \\
\hline$a_{3}$ & $2.17 \times 10^{-5}$ & $9.19 \times 10^{-3}$ \\
\hline
\end{tabular}


of 20,40,60,80 and 100 millimetres with a response time of 10 seconds and to reject the thermal disturbance applied at time $t=35 \mathrm{~s}$. To compare the performances of the two controllers four performance-indicating numbers have been proposed:

- response time of the plant calculated before the thermal perturbation (time after which the error is lower than $5 \%$ of the total displacement)

- RMS error on $t \geq 10 \mathrm{~s}$

- maximal error on $t \geq 10 \mathrm{~s}$

- mean input power on the whole experiment

These numbers have been calculated for the previously described experiments and are given table 3.

We can see in Table 3 that the ten-seconds response time is always achieved in the case of the nonlinear $i$-P whereas in the nonlinear PI case, the response time is greater than $10 \mathrm{~s}$ in three cases. The RMS error and the maximal error are smaller for the nonlinear $i$-P controller. However, the mean power is often slightly smaller for the nonlinear PI controller than for the nonlinear $i$-P controller. 
(a)

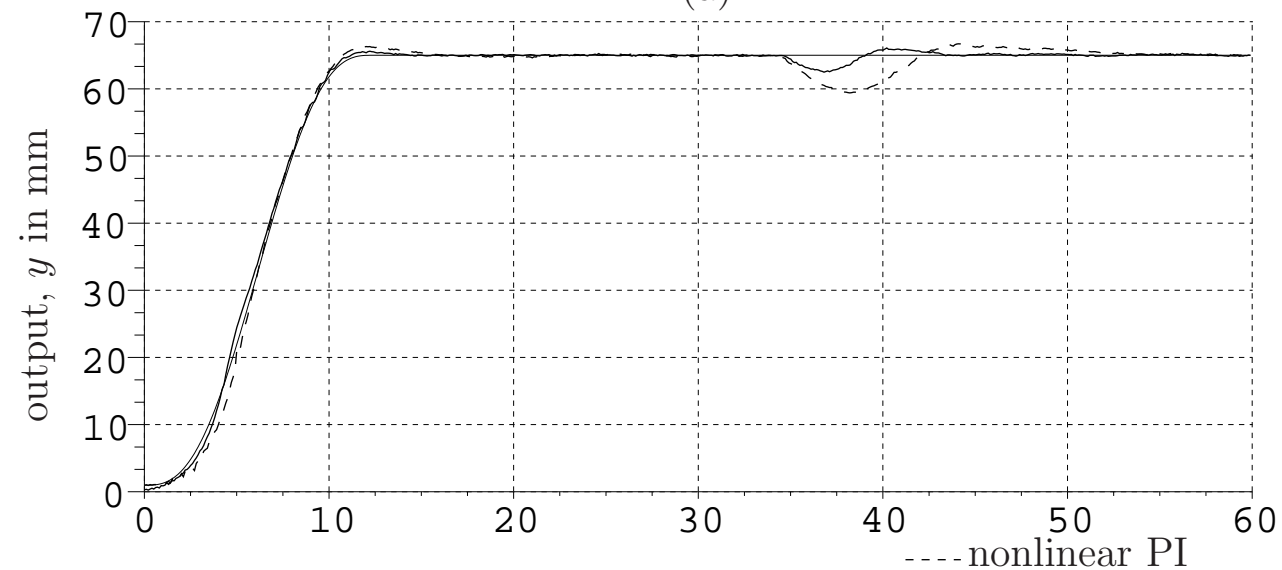

(b)

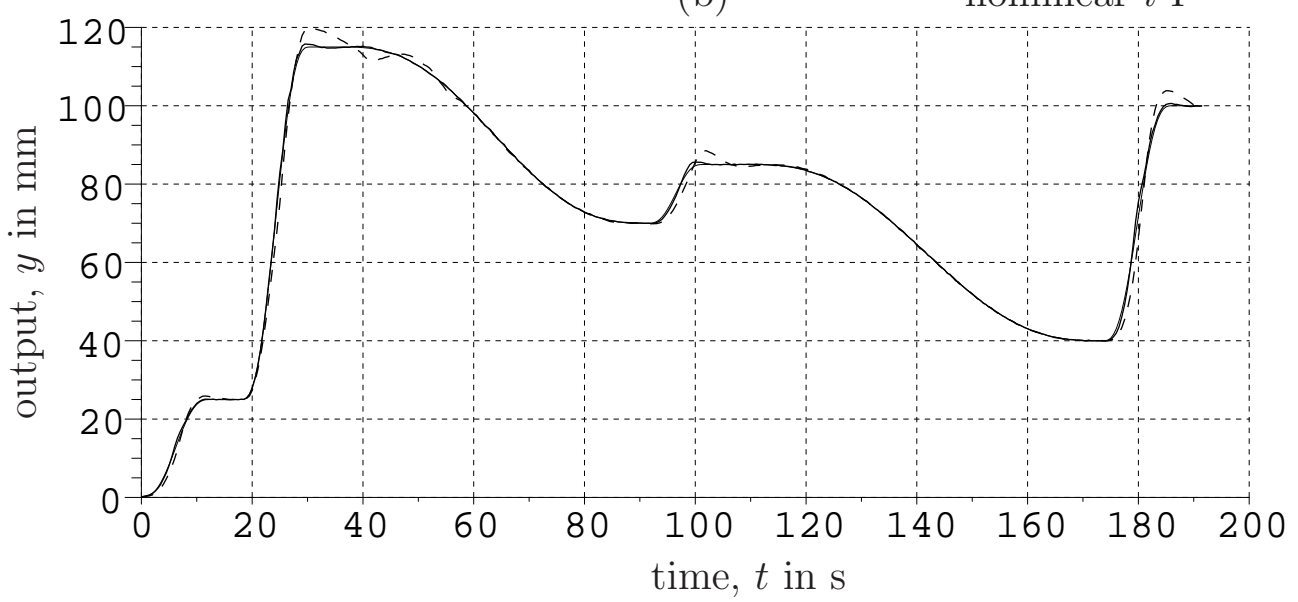

Fig. 7. (a): Output vs time for a trajectory with $65 \mathrm{~mm}$ steady-state level with thermal disturbance (b): Output $v$ s time for a trajectory which is alternatively increasing or decreasing 


\subsubsection{Robustness with respect to hysteresis effect}

A final experiment has been done to test the robustness of the controllers to hysteresis effects. In this experiment, the output has to track a trajectory which is alternatively increasing or decreasing. The output of the plant versus time is shown Fig. 7-(b) for the two controllers. We note that the performances of the two controllers are still good:

- nonlinear PI case : RMS error $=1.76 \mathrm{~mm}$ and mean power $=0.14 \mathrm{~W}$

- nonlinear $i$-P case : RMS error $=0.51 \mathrm{~mm}$ and mean power $=0.13 \mathrm{~W}$

From these experiments, we can conclude that a trajectory profile is really necessary to avoid problems due to set-points jumps and that information from a very simple model of the plant nonlinearities can improve significantly the performances of a simple linear feed-back. 
Table 3. Performance-indicating numbers obtained for experiments of subsection 4.4 .

\begin{tabular}{|c|c|c|c|c|}
\hline $\begin{array}{c}\text { mass } \\
{[\mathrm{g}]}\end{array}$ & $\begin{array}{c}\text { displacement } \\
{[\mathrm{mm}]}\end{array}$ & indicating numbers & nonlinear PI & nonlinear $i$-P \\
\hline \multirow[t]{13}{*}{280} & \multirow[t]{4}{*}{20} & response time $[\mathrm{s}]$ & 13.87 & 8.05 \\
\hline & & RMS error $[\mathrm{mm}]$ & 1.02 & 0.32 \\
\hline & & maximal error $[\mathrm{mm}]$ & 3.18 & 1.47 \\
\hline & & mean power $[\mathrm{W}]$ & 0.23 & 0.25 \\
\hline & \multirow[t]{4}{*}{40} & response time $[\mathrm{s}]$ & 8.75 & 9.51 \\
\hline & & RMS error $[\mathrm{mm}]$ & 1.03 & 0.37 \\
\hline & & maximal error $[\mathrm{mm}]$ & 3.57 & 1.78 \\
\hline & & mean power $[\mathrm{W}]$ & 0.36 & 0.40 \\
\hline & \multirow[t]{4}{*}{60} & response time $[\mathrm{s}]$ & 9.51 & 9.71 \\
\hline & & RMS error $[\mathrm{mm}]$ & 1.31 & 0.50 \\
\hline & & maximal error $[\mathrm{mm}]$ & 4.33 & 2.36 \\
\hline & & mean power $[\mathrm{W}]$ & 0.39 & 0.42 \\
\hline & 80 & response time $[\mathrm{s}]$ & 9.46 & 9.64 \\
\hline
\end{tabular}


- Continued from previous page

\begin{tabular}{|c|c|c|c|c|}
\hline $\begin{array}{c}\text { mass } \\
{[\mathrm{g}]}\end{array}$ & $\begin{array}{c}\text { reference } \\
{[\mathrm{mm}]}\end{array}$ & indicating numbers & nonlinear PI & nonlinear $i$-P \\
\hline & & RMS error $[\mathrm{mm}]$ & 1.53 & 0.58 \\
\hline & & maximal error $[\mathrm{mm}]$ & 4.50 & 3.10 \\
\hline & & mean power $[\mathrm{W}]$ & 0.45 & 0.45 \\
\hline & 100 & response time $[\mathrm{s}]$ & 9.66 & 9.91 \\
\hline & & RMS error $[\mathrm{mm}]$ & 2.00 & 0.76 \\
\hline & & maximal error $[\mathrm{mm}]$ & 5.35 & 4.18 \\
\hline & & mean power $[\mathrm{W}]$ & 0.51 & 0.56 \\
\hline \multirow[t]{8}{*}{360} & \multirow[t]{4}{*}{20} & response time $[\mathrm{s}]$ & 11.6 & 9.33 \\
\hline & & RMS error $[\mathrm{mm}]$ & 0.65 & 0.27 \\
\hline & & maximal error $[\mathrm{mm}]$ & 2.25 & 1.36 \\
\hline & & mean power $[\mathrm{W}]$ & 0.29 & 0.29 \\
\hline & \multirow[t]{4}{*}{40} & response time $[\mathrm{s}]$ & 9.25 & 9.78 \\
\hline & & RMS error $[\mathrm{mm}]$ & 0.69 & 0.39 \\
\hline & & maximal error $[\mathrm{mm}]$ & 2.77 & 1.78 \\
\hline & & mean power $[\mathrm{W}]$ & 0.39 & 0.43 \\
\hline
\end{tabular}


- Continued from previous page

\begin{tabular}{|c|c|c|c|c|}
\hline $\begin{array}{l}\text { mass } \\
{[\mathrm{g}]}\end{array}$ & $\begin{array}{l}\text { reference } \\
\qquad[\mathrm{mm}]\end{array}$ & indicating numbers & nonlinear PI & nonlinear $i$-P \\
\hline & \multirow[t]{4}{*}{60} & response time $[\mathrm{s}]$ & 9.68 & 9.75 \\
\hline & & RMS error $[\mathrm{mm}]$ & 1.20 & 0.50 \\
\hline & & maximal error $[\mathrm{mm}]$ & 4.36 & 2.67 \\
\hline & & mean power $[\mathrm{W}]$ & 0.46 & 0.48 \\
\hline & \multirow[t]{4}{*}{80} & response time $[\mathrm{s}]$ & 9.72 & 9.97 \\
\hline & & RMS error $[\mathrm{mm}]$ & 1.57 & 0.62 \\
\hline & & maximal error $[\mathrm{mm}]$ & 5.18 & 3.25 \\
\hline & & mean power $[\mathrm{W}]$ & 0.51 & 0.55 \\
\hline & \multirow[t]{4}{*}{100} & response time $[\mathrm{s}]$ & 9.86 & 9.54 \\
\hline & & RMS error $[\mathrm{mm}]$ & 1.93 & 0.87 \\
\hline & & maximal error $[\mathrm{mm}]$ & 5.45 & 4.02 \\
\hline & & mean power $[\mathrm{W}]$ & 0.66 & 0.71 \\
\hline \multirow[t]{3}{*}{450} & \multirow[t]{3}{*}{20} & response time $[\mathrm{s}]$ & 25.02 & 9.48 \\
\hline & & RMS error $[\mathrm{mm}]$ & 0.81 & 0.18 \\
\hline & & maximal error $[\mathrm{mm}]$ & 3.32 & 0.93 \\
\hline
\end{tabular}


- Continued from previous page

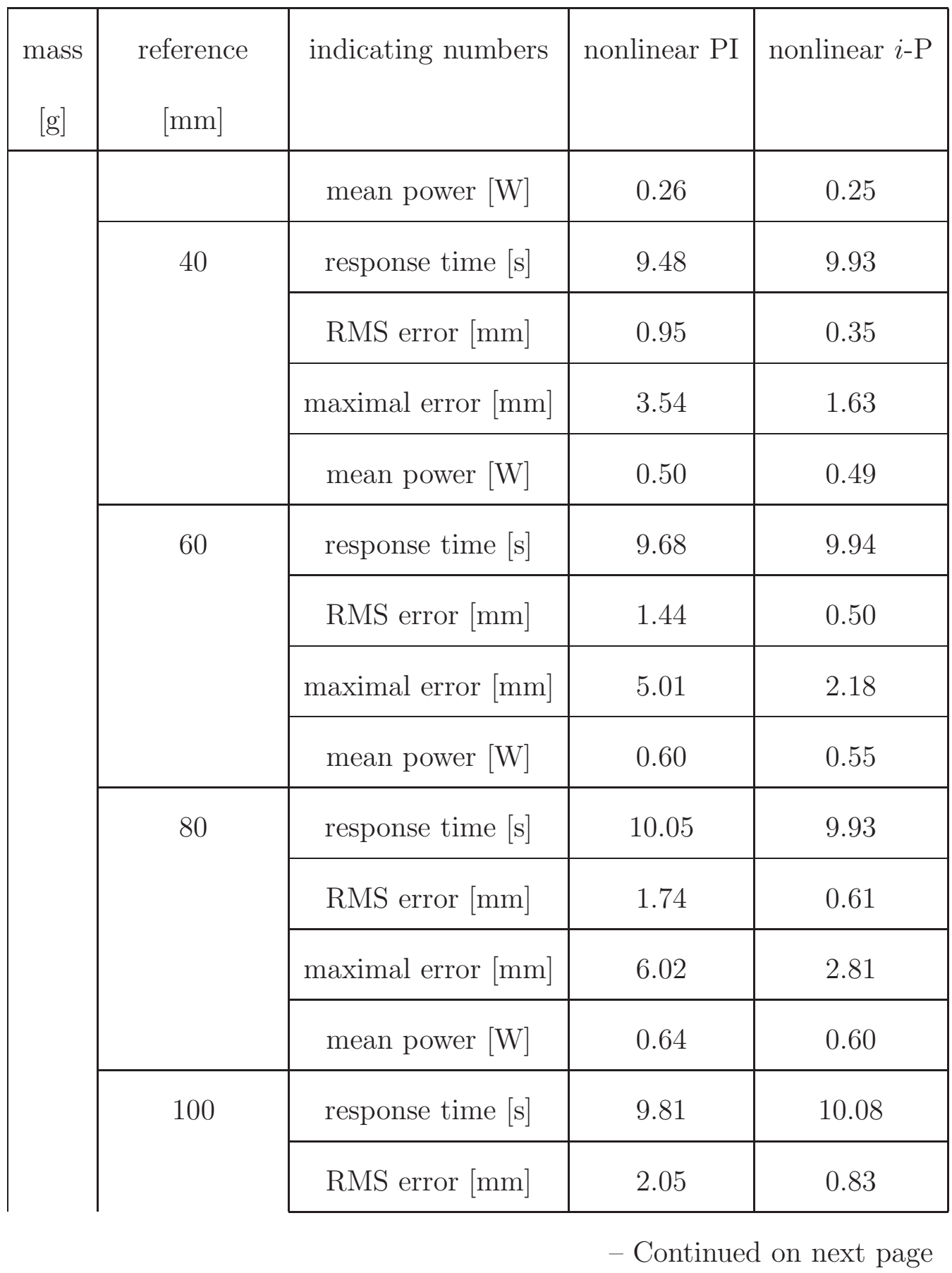


- Continued from previous page

\begin{tabular}{|c|c|c|c|c|}
\hline $\begin{array}{c}\text { mass } \\
{[\mathrm{g}]}\end{array}$ & $\begin{array}{c}\text { reference } \\
{[\mathrm{mm}]}\end{array}$ & indicating numbers & nonlinear PI & nonlinear $i$-P \\
\hline & & maximal error $[\mathrm{mm}]$ & 6.25 & 4.34 \\
\cline { 3 - 5 } & & mean power $[\mathrm{W}]$ & 0.71 & 0.71 \\
\hline
\end{tabular}

\section{Conclusion}

The contribution of the paper is twofold: it presents a convincing application of the new model-free control in the area of SMA actuators control, a field in which model-based control is especially difficult to develop.

Secondly, in order to improve performances of a $i$-P and a PI controller, the paper exposes a general input-output nonphysical model, off-line identified, which is used to design a nonlinear MFC-based controller and a nonlinear PI controller.

Experimental results on a SMA spring based actuators show good tracking performances and good robustness towards thermal disturbances and mass variations for the two controllers. Nevertheless, it seems that the MFC-based 
controller outperforms nonlinear PI. Finally, we are quite confident to be able to efficiently control SMA micro actuators as micro servo-motors in a near future.

\section{References}

Ahn, K. K., Kha, N. B., 2007. Internal model control for shape memory alloy actuators using fuzzy based Preisach model. Sensors and Actuators A 18, $141-152$.

Ang, K. H., Chong, G., Li, Y., 2005. PID control system analysis, design and technology. IEEE transactions on control systems technology 13 (4), $559-526$.

Arbab Chirani, S., Aleong, D., Dumont, C., McDowell, D., Patoor, E., 2003. Superelastic behavior modeling in shape memory alloys. Journal de Physique IV 112, 205-208.

Åström, K. J., Hägglund, T., 1995. PID Controllers: Theory, Design, and Tuning, 2nd Edition. Instrument Society of America Press, Research Triangle Park, NC. 
Åström, K. J., Hägglund, T., 2001. The future of PID control. Control Engineering Practice 9, 1163-1175.

Åström, K. J., Hägglund, T., 2005. Advanced PID Control. ISA - The Instrumentation, Systems, and Automation Society, Research Triangle Park, NC 27709.

Asua, E., Etxebarria, V., Garcia Arribas, A., 2008. Neural network based micropositioning control of smart shape memory alloy actuators. Engineering Applications of Artificial Intelligence 21, 796-804.

Benzaoui, H., Chaillet, N., Lexcellent, C., Bourjault, A., 1999. Nonlinear motion and force control of shape memory alloy actuators. Smart structures and materials 3667, 337-348.

Bouvet, C., Calloch, S., Lexcellent, C., 2004. A phenomenological model for pseudoelasticity of shape memory alloys under multiaxial proportional and nonproportional loadings. European Journal of Mechanics A/Solids $23,37-61$.

Calin, M., Bertsch, A., Chaillet, N., Zissi, S., Ballandras, S., Andre, J. C., Bourjault, A., Hauden, D., September 1997. Microrobots realized by microstereophotolithography and actuated byshape memory alloys. In: Pro- 
ceedings of the 1997 IEEE/RSJ Intelligent Robots and Systems. Grenoble, France, pp. 33-34.

Da Silva, E. P., 2007. Beam shape feedback control by means of a shape memory actuator. Materials and design, Elsevier Science Ltd 28, 15921596.

Dutta, S. M., Ghorbel, F. H., Dabney, J. B., 2005. Modeling and control of a shape memory alloy actuator. In: International Symposium on Intelligent Control. Limassol, Cyprus, pp. 1007-1012.

Fliess, M., Join, C., 2009. Model-free control and intelligent PID controllers: towards a possible trivialization of nonlinear control? In: 15th IFAC Symposium on System Identification (SYSID 2009). IFAC, Saint-Malo France. URL http://hal.inria.fr/inria-00372325/en/

Fliess, M., Join, C., Mboup, M., Sira-Ramìrez, H., 2006. Vers une commande multivariable sans modèle. In: Proc. Conférence internationale francophone d'automatique (CIFA'06).

URL http://hal.inria.fr/inria-00001139/fr/

Fliess, M., Join, C., Sira-Ramírez, H., 2008. Non-linear estimation is easy. International Journal of Modelling, Identification and Control (IJMIC) 
$4(1), 12-27$.

URL http://hal.inria.fr/inria-00158855/fr/

Fliess, M., Lévine, J., Martin, P., Rouchon, P., 1995. Flatness and defect of non-linear systems: introductory theory and examples. Internat. J. Control $61(6), 1327-1361$.

Gédouin, P.-A., Join, C., Delaleau, E., Bourgeot, J.-M., Arbab Chirani, S., Calloch, S., 2008. Model-free control of shape memory alloys antagonistic actuators. In: 17th IFAC World Congress. Seoul, Korea.

URL http://hal.inria.fr/inria-00261891/en/

Gédouin, P.-A., Join, C., Delaleau, E., Bourgeot, J.-M., Arbab Chirani, S., Calloch, S., 2009. A new control strategy for shape memory alloys actuators. In: 8th European Symposium on Martensitic Transformations (ESOMAT'09). Prague, Czech Republic.

Gyöngy, I., Clarke, D. D., 2006. On the automatic tuning and adaptation of PID controllers. Control Engineering Practice 14 (2), 149-163.

Hagenmeyer, V., Delaleau, E., 2003a. Exact feedforward linearization based on differential flatness. Internat. J. Control 76, 537-556. 
Hagenmeyer, V., Delaleau, E., 2003b. Robustness analysis of exact feedforward linearization based on differential flatness. Automatica J. IFAC 39, 1941-1946.

Hagenmeyer, V., Delaleau, E., 2008. Continuous-time non-linear flatnessbased predictive control: an exact feedforward linearisation setting with an induction drive example. Internat. J. Control, 81(10), 1645-1663.

Hagenmeyer, V., Delaleau, E., 2010. Robustness Analysis with Respect to Exogenous Perturbations for Flatness-Based Exact Feedforward Linearization. IEEE Trans. Automatic Control. 55 (3), 727-731

Han, J., 2009. From PID to active disturbance rejection control. IEEE transactions on industrial electronics 56, 900-906.

Jänker, P., Claeyssen, F., Grohmann, B., Christmann, M., Lorkowski, T., LeLetty, R., Sosniki, O., June 2008. New actuators for aircraft and space applications. In: 11th International Conference on New Actuators. Bremen, Germany.

Jayender, J., Patel, R., Nikumb, S., Ostojic, M., December 2005. H $\infty$ loop shaping controller for shape memory alloy actuators. In: Proceedings of 
the 44th IEEE Conference on Decision and Control, and the European Control Conference 2005. Seville, Spain.

Join, C., Masse, J., Fliess, M., 2006. Commande sans modèle pour l'alimentation de moteurs : résultats préliminaires et comparaisons. In: Proc. $2^{e}$ Journées Identification et Modélisation Expérimentale (JIME’06). Poitiers, France.

URL http://hal.inria.fr/inria-00096695/fr/

Join, C., Masse, J., Fliess, M., 2008. Étude préliminaire d'une commande sans modèle pour papillon de moteur. Journal européen des systèmes automatisés (JESA) 42, 337-354.

URL http://hal.inria.fr/inria-00187327/fr/

Khodabakhshian, A., Edrisi, M., 2008. A new robust PID load frequency controller. Control Engineering Practice 16 (9), 1069-1080.

Kohl, M., Krevet, B., Just, E., 2002. Sma microgripper system. Sens. Actuators A Phys 97-98, 646-652.

Leclerc, S., Lexcellent, C., 1996. A general macroscopic description of the thermomechanical behaviour of shape memory alloy. Journal of the Mechanics and Physics of Solids 44 (6), 953-980. 
Lévine, J., 2009. Analysis and Control of Nonlinear Control Systems: A Flatness-based Approach. Springer-Verlag, Berlin.

Madill, D. R., Wang, D., July 1998. Modeling and $l 2$-stability of a shape memory alloy position control system. IEEE Trans. Control Systems Technology 6 (4), 473-481.

Majima, S., Kodama, K., Hasegawa, T., 2001. Modeling of shape memory alloy actuator and tracking control system with the model. IEEE Trans. Control Systems Technology 9, 54-59.

Mboup, M., Join, C., Fliess, M., June 2007. A revised look at numerical differentiation with an application to nonlinear feedback control. In: 15th Mediterrean Conference on Control and Automation (MED'07). Athenes, Greece.

URL http://hal.inria.fr/inria-00142588/fr/

Mboup, M., Join, C., Fliess, M., 2008. Numerical differentiation with annihilators in noisy environment. Numerical Algorithms 50 (4), 439-467.

URL http://hal.inria.fr/inria-00319240/fr/

Mikusiński, J., 1983. Operational calculus, 2nd Edition. PWN \& Oxford University Press. 
O'Dwyer, A., 2006. Handbook of PI and PID controller tuning rules, 2nd Edition. Imperial College Press.

Panagopoulos, H., Åström, K. J., Hägglund, T., 2002. Design of PID controllers based on constrained optimisation. IEE Proceedings - Control Theory \& Applications 149 (1), 32-40.

Patoor, E., Eberhardt, A., Berveiller, M., 1994. Micromechanical modelling of the shape memory behavior. Mechanics of phase transformation and shape memory alloys 189, 23-37.

Peirs, J., Reynaerts, D., Van Brussel, H., June 2002. A retrospective evolution of a sma microactuation. In: Proceedings of The International conference on new actuator. Bremen, Germany, pp. 77-80.

Ram, V., Xiaobo, T., P.S., K., June 2005. Approximate inversion of the Preisach hysteresis operator with application to control of smart actuators. IEEE Trans. Automatic Control 50 (5), 798-809.

Reger, J. and Jouffroy, J. 2008. Algebraische Ableitungsschätzung im Kontext der Rekonstruierbarkeit. Automatisierungstechnik, 58, 324-331.

Romano, R., Aoun Tannuri, E., 2009. Modeling, control and experimental 
validation of a novel actuator based on shape memory alloys. Mechatronics In Press, Corrected Proof.

Ru, C., Chen, L., Shao, B., Rong, W., Sun, L., 2009. A hysteresis compensation method of piezoelectric actuator: Model, identification and control. Control Engineering Practice In Press, Corrected Proof.

Shameli, E., Alasty, A., Salaarieh, H., 2005. Stability analysis and nonlinear control of a miniature shape memory alloy actuator for precise applications. Mechatronics 15, 471-486.

Sira-Ramírez, H., Agrawal, S. K., 2004. Differentially Flat Systems. Marcel Dekker, New York (NJ).

Šittner, P., Vokoun, D., Dayananda, G. N., Stalmans, R., 2000. Recovery stress generation in shape memory $\mathrm{ti}_{50} \mathrm{ni}_{45} \mathrm{Cu}_{5}$ thin wires. Materials Science and Engineering A 286, 298-311.

Song, G., Chaudhry, V., Batur, C., 2003. Precision tracking control of shape memory alloy actuators using neural networks and sliding mode based robust controller. Smart materials and structures 12, 223-231. 
Tan, X., Baras, J. S., 2004. Modeling and control of hysteresis in magnetostrictive actuators. Automatica 40, 1469-1480.

Tavakoli, S., Griffin, I., Fleming, P. J., 2006. Tuning of decentralised PI (PID) controllers for TITO processes. Control Engineering Practice 14 (9), 1069 $-1080$.

Visioli, A., 2005. Design and tuning of a ratio controller. Control Engineering Practice 13, 485-497.

Visioli, A., 2006. Practical PID Control. Advances in Industrial Control. Springer, London (UK).

Wang, Q., Su, C.-Y., 2006. Robust adaptive control of a class of nonlinear systems including actuator hysteresis with Prandtl-Ishlinskii presentations. Automatica 42, 859-867.

Zehetner, J. Reger, J. Horn, M., 2007. A Derivative Estimation Toolbox based on Algebraic Methods - Theory and Practice. IEEE 2007 Multiconference on Systems and Control (MSC 2007). Singapore.

Zehetner, J. Reger, J. Horn, M., 2007. Echtzeit-Implementierung eines alge- 
braischen Ableitungsschtzverfahrens. Automatisierungstechnik, 55, 553560. 